\title{
Yeasts preservation: alternatives for lyophilisation
}

\author{
Loveness K. Nyanga $\cdot$ Martinus J. R. Nout $\cdot$ \\ Eddy J. Smid • Teun Boekhout • Marcel H. Zwietering
}

Received: 13 June 2012/ Accepted: 22 June 2012/Published online: 7 July 2012

(C) The Author(s) 2012. This article is published with open access at Springerlink.com

\begin{abstract}
The aim of the study was to compare the effect of two low-cost, low technology traditional methods for drying starter cultures with standard lyophilisation. Lyophilised yeast cultures and yeast cultures preserved in dry rice cakes and dry plant fibre strands were examined for viable cell counts during 6 months storage at 4 and $25^{\circ} \mathrm{C}$. None of the yeast cultures showed a significant loss in viable cell count during 6 months of storage at $4{ }^{\circ} \mathrm{C}$ upon lyophilisation and preservation in dry rice cakes. During storage at $25{ }^{\circ} \mathrm{C}$ in the dark, yeast cultures preserved in dry rice cakes, and lyophilised cultures of Saccharomyces cerevisiae and Issatchenkia orientalis showed no significant loss of viable cells up to 4 months of storage. Yeast cultures preserved in dry plant fibre strands had the greatest loss of viable count during the 6 months of storage at $25{ }^{\circ} \mathrm{C}$. Preservation of yeasts cultures in dry rice cakes provided better survival during storage at $4{ }^{\circ} \mathrm{C}$ than lyophilisation. The current study demonstrated that traditional methods can be useful and effective for starter culture preservation in small-scale, low-tech applications.
\end{abstract}

Keywords Yeasts preservation - Starter culture · Lyophilisation · Rice cake · Plant fibre

\footnotetext{
L. K. Nyanga

Institute of Food, Nutrition and Family Sciences,

University of Zimbabwe, Harare, Zimbabwe

L. K. Nyanga · M. J. R. Nout · E. J. Smid ( $₫)$.

M. H. Zwietering

Laboratory of Food Microbiology, Wageningen

University, Wageningen, The Netherlands

e-mail: eddy.smid@wur.nl

T. Boekhout

CBS-KNAW Fungal Biodiversity Centre, Utrecht,

The Netherlands
}

\section{Introduction}

The basic concept of microbial preservation of starter cultures is to avoid any change in the genetic, physiological and morphological characteristics of the microorganisms during storage and to promote a complete depression of all metabolic activity (Cheong et al. 2008). Lyophilisation is one of the most successful methods for preserving bacteria, yeasts and sporulating fungi (Spadaro et al. 2010; Tan et al. 2007). This method offers convenience of storage and postage, and it keeps the microorganisms viable for long periods of time (Miyamoto-Shinohara et al. 2006). However, lyophilisation is relatively expensive as it requires sophisticated equipment and adequate power supply.

Most small and medium-sized enterprises (SME's) in developing countries cannot afford lyophilisation of starter cultures. Traditional methods for starter culture preservation could be an economical and dependable alternative to lyophilisation in low-tech infrastructure conditions. Fermentation of pito, a traditional alcoholic beverage brewed by people from the west African sub-region (Demuyakor and Ohta 1993), uses yeast cells as inoculum originating from a previous brew trapped in the interstices of a traditional woven belt (Sefa-Dedeh et al. 1999). In East Asian countries rice starter cakes which contain complex mixtures of fungi are used for rice wine production (Nout and Aidoo 2002). However, the use of traditional methodologies can result in unpredictable fermentation products as the inocula contain uncontrolled mixed microbiota. As a result, even when the fermentation process is successful, its outcome could show considerable variation in product quality. These traditional starter preservation methods could be harnessed for dependable and low-cost preservation of defined fermentation starter cultures. Since the traditional methods are usually economically feasible and 
can be applied under rural conditions, the basic work flow of these processes is preferably kept intact.

This study was designed to assess two traditional methods for drying defined starter cultures, i.e., stabilization of yeast cultures in plant fibre strands and in rice cakes, for subsequent use in masau wine production and compare these methods with lyophilisation. For this case study, we used yeast isolates previously isolated from the traditionally fermented Ziziphus mauritiana (masau) fruit pulp (Nyanga et al. 2007). In Zimbabwe, the fermented masau fruit pulp is subsequently distilled into a spirit called kachasu (Nyanga et al. 2008).

\section{Materials and methods}

Preparation of the inoculum

Cultures used in this study were Saccharomyces cerevisiae (strains 38 and 153), Saccharomycopsis fibuligera (66) and Issatchenkia orientalis (129). These strains were previously isolated from traditionally fermented masau fruit pulp (Nyanga et al. 2007) and were maintained routinely at $-80{ }^{\circ} \mathrm{C}$ in $300 \mathrm{~mL} \mathrm{~L}^{-1}$ glycerol prepared in peptone physiological saline (PPS) $\left[\mathrm{NaCl} 8.5 \mathrm{~g} \mathrm{~L}^{-1}\right.$ (Merck, Darmstadt, Germany), neutral peptone $1 \mathrm{~g} \mathrm{~L}^{-1}$ (Oxoid, Basingstoke, UK)].

Yeast cells were grown on Malt Extract Agar (MEA) (Oxoid, Basingstoke, UK) slants at $30{ }^{\circ} \mathrm{C}$ for $48 \mathrm{~h}$. A suspension of yeast cells was made by adding $2 \mathrm{~mL}$ of sterile PPS onto each pure culture slant. The biomass was gently scraped off the agar by means of an inoculating loop. The yeast cell suspension was then transferred to a sterile tube and used as described below for each preservation method. A fresh yeast culture was made for each method.

\section{Preservation methods}

For each preservation method two independent experiments were performed as described below.

\section{Lyophilisation}

Yeast suspensions of $1 \mathrm{~mL}$ volume were transferred to sterile Eppendorf tubes and centrifuged for $10 \mathrm{~min}$ at $2,600 \times g$ (Cheong et al. 2008). The cells were then washed and centrifuged thrice in $1 \mathrm{~mL}$ sterile PPS. The pellet was then suspended in $1 \mathrm{~mL}$ sterile solution of $120 \mathrm{~g} \mathrm{~L}^{-1}$ fat free instant milk powder (Clover SA Pty Ltd, Roodepoort, South Africa) prepared in sterile distilled water supplemented with $70 \mathrm{~g} \mathrm{~L}^{-1}$ trehalose (Sigma-Aldrich Co., St Louis, MO, USA) (Cheong et al. 2008; Wiemken 1990; Tan et al. 2007). The yeast-milk suspension $(0.2 \mathrm{~mL})$ was transferred to sterile cryotubes. The cryotubes were kept at $-58{ }^{\circ} \mathrm{C}$ for $3 \mathrm{~h}$ and were then lyophilised for $3 \mathrm{~h}$ in a lyophilisation apparatus (Edwards Freeze dryer-Modulyo model 4 k, Crawley, West Sussex, England). After freezedrying the cryotubes were sealed.

\section{Rice cakes}

Rice flour was made from white polished rice using a pulveriser mill (Siebtechnik GmbH, Mülheim Ruhr, Germany). Portions of rice flour $(50 \mathrm{~g})$ were made into a $40 \%$ moisture content dough was made using sterile water according to Dung et al. (2005). The dough from each flask was inoculated with $8 \mathrm{~mL}$ of yeast suspension and incubated at $30{ }^{\circ} \mathrm{C}$ for $24 \mathrm{~h}$. The inoculated rice dough was then aseptically made into cakes of about 3-4 cm diameter and $5-6 \mathrm{~mm}$ thickness. The cakes were aseptically dried at $40{ }^{\circ} \mathrm{C}$ in a ventilated oven for $5 \mathrm{~h}$ to reach a moisture content of about $4-5 \% \mathrm{w} / \mathrm{w}$ and then placed in tightly closed containers.

\section{Plant fibre strands}

The plant fibre belt named Tafanta in Biali language, and made of twined baobab (Adansonia digitata) fibres was obtained from Benin. The plant fibre belt was cut into strands (7-8 $\mathrm{cm}$ length and $6 \mathrm{~mm}$ thickness) that were wrapped in aluminium foil and sterilized at $121{ }^{\circ} \mathrm{C}$ for $15 \mathrm{~min}$. Two hundred $\mathrm{mL}$ of Glucose-Yeast extract broth (GYEB) (glucose $100 \mathrm{~g} \mathrm{~L}^{-1}$, yeast extract $0 \mathrm{~g} \mathrm{~L}^{-1}$ ) was brought into $500 \mathrm{~mL}$ volumetric flasks and sterilized at $121^{\circ} \mathrm{C}$ for $15 \mathrm{~min}$. Sterile strands were added to GYEB aseptically, inoculated with $1 \mathrm{~mL}$ of yeast suspension, whereas a control flask was not inoculated. Broths were fermented for 5 days at $30{ }^{\circ} \mathrm{C}$ under non-aerated conditions, plugged with a water-lock. After fermentation the strands were covered and impregnated with sedimented yeast biomass. They were taken out of the flask under aseptic conditions and dried at $40{ }^{\circ} \mathrm{C}$ in a ventilated oven for $3 \mathrm{~h}$. The dried and yeast impregnated fibre strands were placed in tightly closed containers.

\section{Storage conditions}

The lyophilised yeast cells and dry rice cakes were stored at $4{ }^{\circ} \mathrm{C}$ and room temperature $\left(\approx 25{ }^{\circ} \mathrm{C}\right)$ in a dark cabinet. The dry plant fibre strands were stored at room temperature $\left(\approx 25^{\circ} \mathrm{C}\right)$ in a dark cabinet.

Rehydration and yeast viable cell counts

The survival of the yeast cells was determined by sampling once a week for 1 month and then once every month for 
6 months. Viable cells were also determined immediately after each drying method. The number of viable cells was determined as colony forming units per $\mathrm{mL}\left(\mathrm{CFU} \mathrm{mL}{ }^{-1}\right)$ for the lyophilised yeast cells and as colony forming units per gram $\left(\mathrm{CFU} \mathrm{\textrm {g } ^ { - 1 }}\right)$ for rice cakes and plant fibre strands.

\section{Lyophilisation}

The total content of one cryotube was resuspended in $1 \mathrm{~mL}$ of PPS and vortexed for $1 \mathrm{~min}$ to disintegrate any cell clumps.

\section{Rice cakes}

A sample of $1 \mathrm{~g}$ of rice cake was aseptically transferred into sterile $250 \mathrm{~mL}$ bottles containing $99 \mathrm{~mL}$ of PPS. The bottles were vigorously shaken at intervals by hand for $10 \mathrm{~min}$ to dissolve the cakes.

Plant fibre strands: one strand $(0.5 \mathrm{~g} \pm 0.02)$ was transferred into a sterile $250 \mathrm{~mL}$ bottle containing $50 \mathrm{~mL}$ of PPS. The bottle was vigorously shaken at intervals by hand for $10 \mathrm{~min}$.

\section{Plating}

Pour plates were made using glucose peptone yeast extract agar [20 $\mathrm{g} \mathrm{L}^{-1}$ D-glucose (Merck), $5 \mathrm{~g} \mathrm{~L}^{-1}$ bacto peptone (Oxoid), $5 \mathrm{~g} \mathrm{~L}^{-1}$ yeast extract and $20 \mathrm{~g} \mathrm{~L}^{-1}$ agar (Oxoid); (GPYA)] with appropriate dilutions in duplicate. The inoculated plates were incubated for $48 \mathrm{~h}$ at $30^{\circ} \mathrm{C}$ and colonies were counted by manual enumeration.

Survival rate and calculation of $\mathrm{D}$ values

Loss of viability was calculated as $\log \mathrm{N}_{\mathrm{o}} / \mathrm{N}_{\mathrm{t}}$, where $\mathrm{N}_{\mathrm{o}}$ represents the counts of viable microorganisms immediately after drying, and $\mathrm{N}_{\mathrm{t}}$ the counts of viable microorganisms after a given storage period. Linear regression analysis was carried out on numbers of surviving cells at each storage temperature versus sampling time point. The negative reciprocal of the slope of regression lines was calculated to obtain D values (months). D is the time of the first decimal reduction (i.e., time required to reduce the population by $1 \log$ unit from initial level at $t=0$ ).

\section{Statistical analysis}

The analytical data were analysed using the statistical program SPSS16.0 for Windows (Apache Software Foundation, USA) and the one-way ANOVA model was used applying the LSD test to evaluate significant differences among means.

\section{Results and discussion}

Starter culture preservation, maintenance and distribution are important as the quality of the final fermented product strongly depends on the preservation technologies employed that are required to guarantee long-term maintenance of stable cultures in terms of viability and activity. This demands logistic infrastructure and economic affordability particularly for small-scale, low-tech applications. Thus, in this study we compared the survival of yeast starter cultures preserved by two low-tech traditional methods (i.e., stabilization of yeast cultures in plant fibre strands and in rice cakes), with lyophilisation. Lyophilised yeast cultures and yeast cultures preserved in dry rice cake and dry plant fibre strand were examined for viable cell counts during 6 months storage at 4 and $25{ }^{\circ} \mathrm{C}$ in a dark cabinet. During storage at $4{ }^{\circ} \mathrm{C}$, cultures of the different yeast species all showed a similar survival behaviour with a viable cell count reduction of $<1 \log$ unit after 6 months storage upon either lyophilisation or drying in rice cakes (Fig. 1). Interestingly, dry rice starter cakes showed minimal losses of viable counts for all strains (viz. between 0.2 and $0.3 \operatorname{logs}$ ) as compared to lyophilised cultures, which suffered higher losses of viable counts (viz. between 0.6 and 0.8 logs). This
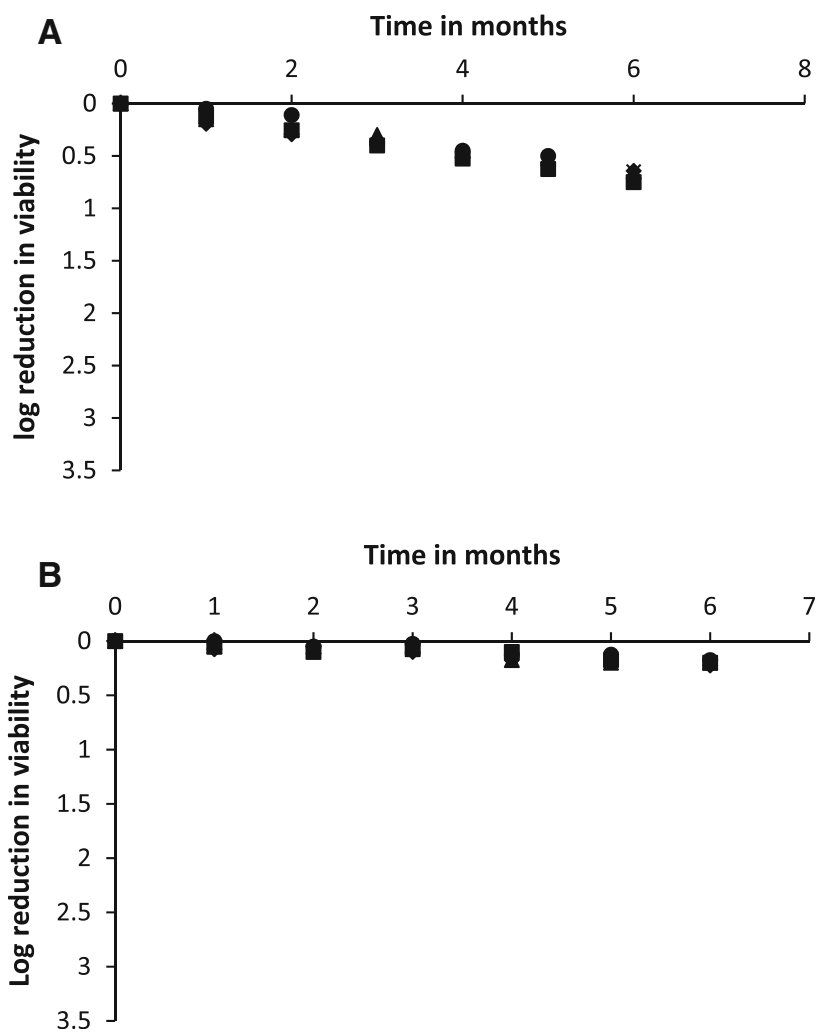

Fig. 1 Log reduction in viable counts of each yeast species in lyophilised (a) and dry rice cake (b) cultures during 6 months storage at $4{ }^{\circ} \mathrm{C}, \mathrm{S}$. cerevisiae (38), S. cerevisiae (153), I. orientalis (129) and, S. fibuligera (66) 
observation was supported by the calculated D values ranging from 28 to 40 months (Table 1), which clearly showed that yeast cells preserved in dry rice cakes survived significantly $(p<0.05)$ better than lyophilised yeast cells which had D values ranging from 8 to 10 months. Cultures of the yeast species showed different D values. For the yeast cultures preserved in dry rice cakes, $S$. fibuligera had the highest D value and $S$. cerevisiae strain 153 had the lowest value. Lyophilised yeast cultures of $S$. cerevisiae strain 38 and $I$. orientalis shared the highest $\mathrm{D}$ value followed by S. fibuligera and lastly $S$. cerevisiae strain 153 .

There was a significant $(p<0.05)$ decrease in viable counts of yeast cultures during the six months of storage for all preservation methods for yeasts stored at $25{ }^{\circ} \mathrm{C}$ (Fig. 2). It was noted that yeast cultures preserved in dry rice cakes had the best retention of viable cell counts with no significant loss up to 4 months of storage for all the strains. Lyophilisation was second best with $S$. cerevisiae (strains 38 and 153) and I. orientalis cultures showing no significant decrease in viable cell counts up to 4 months. On the other hand, lyophilised S. fibuligera cultures performed differently showing a slight loss in viable cell counts during 3 months of storage. Yeast cultures preserved in dry fibre

Table 1 Estimated D values (months) of yeast strains preserved by lyophilisation, in dry rice cakes and dry fibre strands stored at 4 and $25{ }^{\circ} \mathrm{C}$

\begin{tabular}{|c|c|c|c|}
\hline \multicolumn{2}{|c|}{$\begin{array}{l}\text { Preservation method and } \\
\text { yeast strains }\end{array}$} & \multicolumn{2}{|c|}{$\begin{array}{l}\text { Storage temperature } \\
\text { Linear regression } \\
\text { D value }\end{array}$} \\
\hline & Strain no. & $4{ }^{\circ} \mathrm{C}$ & $25^{\circ} \mathrm{C}$ \\
\hline \multicolumn{4}{|l|}{ Lyophilised } \\
\hline S. cerevisiae & 38 & $10 \pm 0.7^{\mathrm{a} 2}$ & $4 \pm 0.6^{\mathrm{a}}$ \\
\hline S. cerevisiae & 153 & $8 \pm 0.96^{\mathrm{b}}$ & $4 \pm 0.11^{\mathrm{a}}$ \\
\hline I. orientalis & 129 & $10 \pm 0.47^{\mathrm{a}}$ & $3 \pm 0.31^{\mathrm{b}}$ \\
\hline S. fibuligera & 66 & $9 \pm 1.02^{\mathrm{c}}$ & $3 \pm 0.01^{\mathrm{b}}$ \\
\hline \multicolumn{4}{|l|}{ Dry rice cakes } \\
\hline S. cerevisiae & 38 & $33 \pm 1.91^{\mathrm{d}}$ & $5 \pm 1.43^{\mathrm{d}}$ \\
\hline S. cerevisiae & 153 & $28 \pm 1.42^{\mathrm{e}}$ & $5 \pm 1.68^{\mathrm{d}}$ \\
\hline I. orientalis & 129 & $31 \pm 1.66^{\mathrm{f}}$ & $4 \pm 0.98^{\mathrm{e}}$ \\
\hline S. fibuligera & 66 & $40 \pm 1.96^{\mathrm{i}}$ & $5 \pm 0.87^{\mathrm{d}}$ \\
\hline \multicolumn{4}{|c|}{ Dry plant fibre strands } \\
\hline S. cerevisiae & 38 & ND & $2 \pm 0.0^{\mathrm{f}}$ \\
\hline S. cerevisiae & 153 & ND & $2 \pm 0.09^{\mathrm{f}}$ \\
\hline I. orientalis & 129 & ND & $2 \pm 0.15^{\mathrm{f}}$ \\
\hline S. fibuligera & 66 & ND & $2 \pm 0.0^{\mathrm{f}}$ \\
\hline
\end{tabular}

${ }^{1} \mathrm{D}$ values \pm standard deviation shown are means of two replicate experiments, the enumeration was done in duplicate

${ }^{2}$ Means in the same column with same letter are not significantly different according to the LSD at 0.05 level

$N D$ not determined strands suffered the greatest loss of viable counts as there was significant decrease in viable cell count (between 1.2 and $1.3 \log \mathrm{CFU} \mathrm{g}{ }^{-1}$ ) after 3 months of storage. The D values of the yeast cultures preserved in dry plant fibre strands were also lower compared to those obtained from lyophilised cultures and cultures preserved in dry rice cakes.

The results indicated that survival of the yeasts was better at 4 than at $25^{\circ} \mathrm{C}$ for both the lyophilised cultures and yeast cultures preserved in dry rice cakes. According to Spadaro et al. (2010) this could be due to the fact that low temperature helps to keep the metabolic activity at a low level which is expected to contribute to an increase in
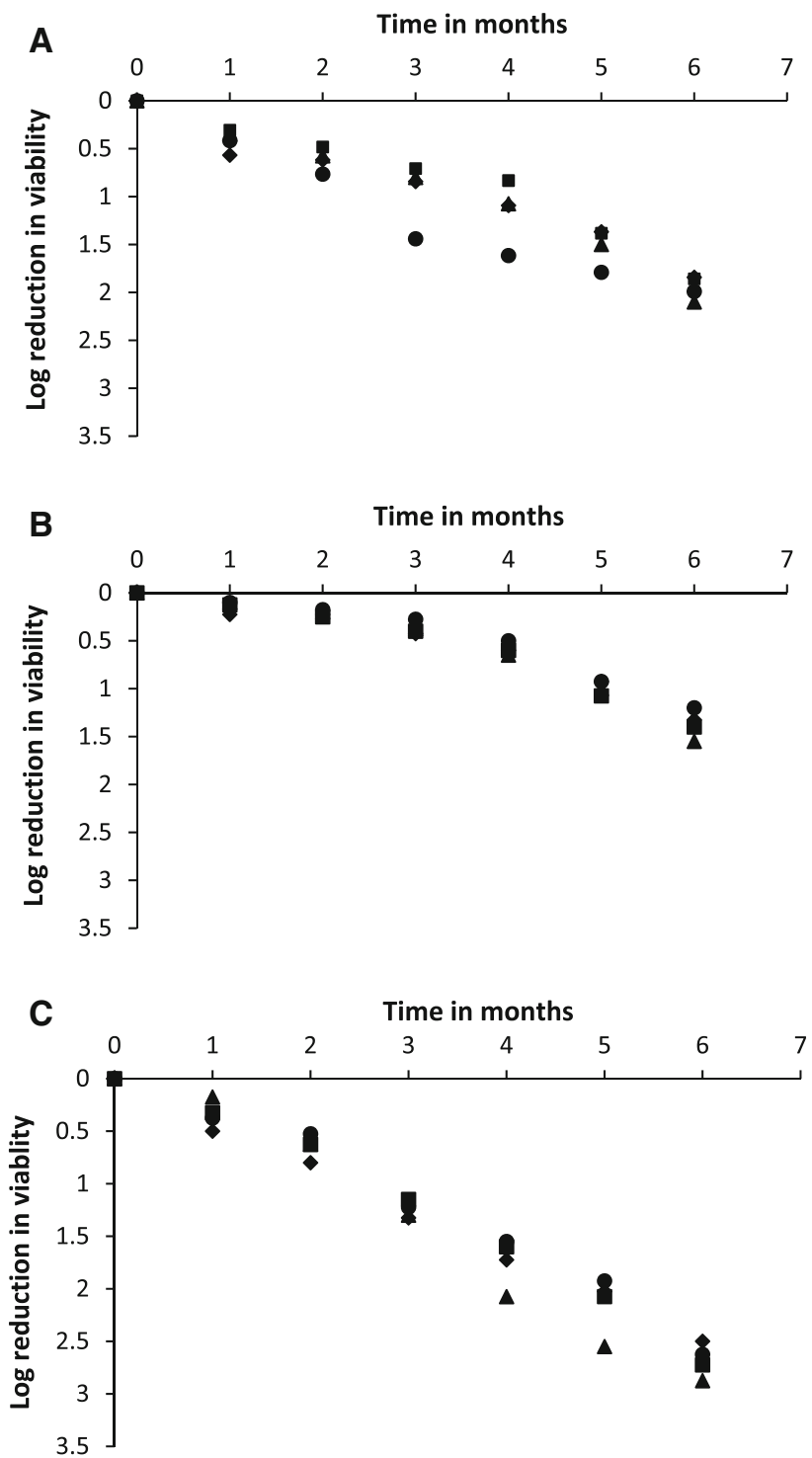

Fig. 2 Log reduction in viable count of each yeast species in lyophilised (a), dry rice cake (b) and dry plant fibre strand (c) cultures during 6 months storage at $25^{\circ} \mathrm{C}, \mathrm{S}$. cerevisiae (38), S. cerevisiae (153), I. orientalis (129) and, S. fibuligera (66) 
storage and shelf-life. Better survival of lyophilised microorganisms stored at $4{ }^{\circ} \mathrm{C}$ than at $25{ }^{\circ} \mathrm{C}$ was reported in several studies (Abadias et al. 2001; De Valdez and Diekmann 1993; Li and Tian 2007; Spadaro et al. 2010). Loss of viability during storage of dried cultures of microbial cells has been attributed to lipid oxidation of cell membrane fatty acids (Coulibaly et al. 2009). This would be initiated by loss of water that increases the ionic concentration, which can lead to the formation of reactive oxygen species. Subsequently, these oxygen species can damage proteins, modify nucleobases and sugars in deoxyribonucleic acid and eventually cause lipid oxidation.

Skimmed milk and trehalose were used in this study as cryoprotectants for the yeast cultures during lyophilisation. The combination of skimmed milk with disaccharides has been reported to improve the viability and stability of micro-organisms during lyophilisation and storage ( $\mathrm{Li}$ and Tian 2007; Tan et al. 2007). Direct interactions between sugar molecules and membrane phospholipids, or sugar molecules and proteins, and vitrification of sugars in the dry state are thought to be the main protective mechanisms (Crowe et al. 1998).

In this study, dry rice cakes provided the best retention of viable cell counts for the yeast cultures. Rice contains starch, which comprises amylose and amylopectin that could have provided hydroxyl groups as reactive groups for attachment to the yeast cells and possibly by the formation of a glass structure, hence protecting the yeast cells from damage. Mazzobre et al. (1999) reported that saccharides are able to form a glassy structure, in which the sensitive components of the membrane are embedded.

The preservation of starter cultures by a simple and adoptable technology using locally available substrates such as grains and pulses that are familiar to the consumers, would be compatible with the existing low level of technology (Isu and Abu 2000) in most developing countries.

\section{Conclusion}

Dry rice cake cultures retained viable cell counts significantly better as compared to lyophilised cultures. Traditional culture preservation methods, such as those using dry rice cakes and dry plant fibres can be applied to preserve defined starter cultures for traditional fermented foods. In order to safeguard the quality of the preserved yeast, the preservation should be carried out under hygienic and controlled conditions. The use of dry rice cakes and plant fibre strands as preservation methods are of interest in small-scale, low-tech applications.

Acknowledgments The financial support by the McGillavry Fund of the Royal Netherlands Academy of Arts and Sciences (KNAW,
Grant No. ISK/9495/MacGillavry) and the International Foundation for Science (IFS Grant No. C/3737), is gratefully acknowledged. The authors thank Dr. Polycarpe Kayodé, University of Abomey-Calavi, Benin, for kindly providing the plant fibre belt. We are also grateful to the technical assistance given by Mr. P. Gombiro.

Open Access This article is distributed under the terms of the Creative Commons Attribution License which permits any use, distribution, and reproduction in any medium, provided the original author(s) and the source are credited.

\section{References}

Abadias M, Teixido N, Usall J, Benabarre A, Vinas I (2001) Viability, efficacy, and storage stability of freeze-dried biocontrol agent Candida sake using different protective and rehydration media. J Food Prot 64:856-861

Cheong C, Wackerbauer K, Beckmann M, Jang KH, Kang SA (2008) Effect of cultivation conditions on trehalose content and viability of brewing yeast following preservation via filter paper or lyophilization methods. Biotechnol Bioprocss Eng 13:690-696

Coulibaly I, Amenan AY, Lognay G, Fauconnier M, Thonart P (2009) Survival of freeze-dried Leuconostoc mesenteroides and Lactobacillus plantarum related to their cellular fatty acids composition during storage. Appl Biochem Biotechnol 157:70-84

Crowe JH, Carpenter JF, Crowe LM (1998) The role of vitrification in anhydrobiosis. Annu Rev Physiol 60:73-103

De Valdez GF, Diekmann H (1993) Freeze-drying conditions of starter cultures for sourdoughs. Cryobiology 30:185-190

Demuyakor B, Ohta Y (1993) Characteristics of single and mixed culture fermentation of pito beer. J Sci Food Agric 62:401-408

Dung NTP, Rombouts FM, Nout MJR (2005) Development of defined mixed-culture fungal fermentation starter granulate for controlled production of rice wine. Innov Food Sci Emerg Technol 6:429-441

Isu NR, Abu GO (2000) An evaluation of the effect of Bacillus cells and Bacillus spores in association with cowpea granules as starter cultures for the fermentation of African oil bean (Pentaclethra macrophylla Bentham) to 'ugba'. Plant Foods Hum Nutr 55:127-138

Li BQ, Tian SP (2007) Effect of intracellular trehalose in Cryptococcus laurentii and exogenous lyoprotectants on its viability and biocontrol efficacy on Penicillium expansum in apple fruit. Lett Appl Microbiol 44:437-442

Mazzobre MF, Lodato P, De Huergo MS, Buera MP, Chirife J (1999) The performance of maltodextrins as protective excipients in freeze-dried biomaterials subjected to thermal treatment, in comparison with trehalose systems. In: Colonna P, Guilbert S (eds) Biopolymer science: food and non food applications, vol 91. Colloques de I'INRA, France, pp 321-325

Miyamoto-Shinohara Y, Sukenobe J, Imaizumi T, Nakahara T (2006) Survival curves for microbial species stored by freeze-drying. Cryobiology 52:27-32

Nout MJR, Aidoo KE (2002) Asian fungal fermented food. In: Osiewacz HD (ed) The Mycota vol. X "Industrial applications". Springer, Berlin, pp 23-47

Nyanga LK, Nout MJR, Gadaga TH, Theelen B, Boekhout T, Zwietering MH (2007) Yeasts and lactic acid bacteria microbiota from masau (Ziziphus mauritiana) fruits and their fermented fruit pulp in Zimbabwe. Int J Food Microbiol 120:159-166

Nyanga LK, Nout MJR, Gadaga TH, Boekhout T, Zwietering MH (2008) Traditional processing of masau fruits (Ziziphus mauritiana) in Zimbabwe. Ecol Food Nutr 47:95-107 
Sefa-Dedeh S, Sanni AI, Tetteh G, Sakyi-Dawson E (1999) Yeasts in the traditional brewing of pito in Ghana. World J Microbiol Biotechnol 15:593-597

Spadaro D, Ciavorella AA, Lopez-Reyes JG, Garibaldi A, Gullino ML (2010) Effect of culture age, protectants, and initial cell concentration on viability of freeze-dried cells of Metschnikowia pulcherrima. Can J Microbiol 56:809-815
Tan SC, Ingen CW, Stalpers JA (2007) Freeze-drying fungi using a shelf freeze-drier. Cryopreservation and freeze-drying protocols. Methods Mol Biol 368:119-125

Wiemken A (1990) Trehalose in yeast, stress protectant rather than reserve carbohydrate. Antonie Leeuwenhoek 58:209-217 